\title{
ERICH FROMM'S PERSPECTIVE ABOUT LONELINESS AND ITS OUTCOMES IN EDUCATION
}

\author{
Sahar Zabihidan ${ }^{1}$ \\ Babak Shamshiri ${ }^{2}$
}

\begin{abstract}
For many years, the human need for the group, social life, and the impact of this form of life on mental health and body have been discussed. This is said to be less about loneliness and the role played by human beings. Loneliness is a global issue experienced by all humans more or less and with their lives. In other words, many people with races, cultures, social classes, and at different ages and times each experience some kind of loneliness. It is true that human being is an absolute social being and we always hear from the benefits of communication and satisfaction from it, But this should not be overlooked by the constructive and positive aspects of being alone, especially in education systems; Hence, this article was conducted with the aim of examining the opinions and views of Eric Forum on loneliness and analyzing its consequences in education. This
\end{abstract}

research is part of qualitative research, which is done by analytical-deductive method. Findings indicate that Any social person with extensive communication does not necessarily have mental health; On the other hand, loneliness is not always a sign for malicious and anti-social characters, In other words, what is important is the difference between antisocial people and a group consciously choosing loneliness. Therefore, loneliness is an emotional feeling that in the case of balance, it can be constructive and lead to selfknowledge, the development of reflection thinking, self-consciousness and if it is to be extreme, there will be plenty of harm in the community, especially education systems.

Keywords: Erich Fromm, loneliness, positive and negative dimensions of loneliness, education system.

\footnotetext{
1. Ph.D Student of History and Philosophy of Education; Foundations of Education, Psychology and Educational Sciences, Shiraz University, Iran. Email: sahar.zabihidan@gmail.com (Corresponding author) 2 - Associate Prof. of the Dept. of Foundations of Educational Psychology, Shiraz University, Iran. Email: babakshamshiri@yahoo.com
} 


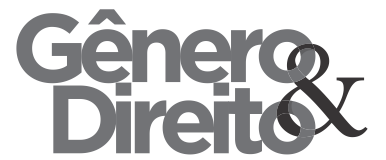

\section{Introduction}

During the $20^{\text {th }}$ century, the human life has undergone rapid and fullscale changes. It should not be forgotten that the social and human conditions of the past centuries have been simpler than today's conditions; thus, the issues are currently more complex and in need of more concentration. In other words, the wonderful nature of the social changes is constantly adding to the complexity and risks of the individuals' life conditions in various communities. These changes cause degrees of distrust, unrest, frustration and loneliness in nearly all individuals. Loneliness is a psychological and philosophical issue and a type of psychological harms that can actually initiate and become the starting point of other social harms; therefore, Asher and Paquette 2003, believe that loneliness can both be a life experience and a potential harm; so, loneliness is one of the complex psychological constructs that have always been discussed and investigated. At that time, loneliness was considered as a positive concept that was interpreted as an individual's voluntary withdrawal from the daily life engagements for reaching more sublime goals (like contemplation, meditation and relationship with the God); but, nowadays, the psychological texts do not approach loneliness as a positive feeling, rather it is envisioned as a state wherein an individual perceives or experiences the absence of relationships with the others and it includes such primary and important elements like the undesirable feeling of the loss or absence of a companion, unpleasant and negative aspects of the lost relationships and losing the quality level of the relationship with the others (De Jong Gierveled, 1998, cited in Salimi, 2009).

Generally, there are few persons who have not experienced loneliness in a period of life even when it comes to the today's generation that, compared with the previous generations, enjoy increasingly more facilities and technologies; it is in such a way that some believe that a person's loneliness has taken a variegated manifestation due to modernism but, anyway, human beings are afraid of becoming lonely. As the founder of the humanist psychology, Erich Fromm realizes modernity as an inevitable process and a world-inclusive phenomenon that has presently captured the entire world because, as he opines, every society finds itself having given a 
way to the modernity movement in its thoughts and ego exactly since the time it rejects the traditions as a model in its daily life. Thus, in Fromm's mind, human's feeling of loneliness in the today's world has been born of the modern world with all the consequences resulting thereof.

Ahmadi 2016, is of the belief that the industrial world and the machine life has inflicted many of the human beings with "loneliness" and "social alienation" and it does not have any special commonality with the virtuous and personal loneliness of the human beings the way it is viewed by a great many of the philosophers. Thus, loneness of the today's modern society, as the most prominent ethical characteristic of individualism, can be considered as the "ailment of the new life".

In Fromm's opinion, the mankind is always in pain for having a history of loneliness, isolation and insignificance. Thus, the humans' essential need is escaping from the isolation, creating sense of attachment and finding meaning for his or her life. On the one hand, the human beings have fought against the nature and the ossified systems for attaining freedom and, on the other hand, these freedoms have led to a feeling of loneliness and severe isolation and, this way, the human beings make efforts, in the meanwhile, to escape such a freedom. Therefore, while fighting for freedom and autonomy, the human beings demand dependence and relationship with the others. The solution to get rid of such a duality of being simultaneously in need of freedom and relationship with others lies in the society's economic structure because, in a modern and capitalist society, the individual freedoms, making of free choices and individual responsibilities are underlined at the cost of deep feelings of isolation and loneliness. So, Erich Fromm knows capitalist society as a "sick society" in his book "The Sane Society" and believes that this society has afflicted the mankind with selfalienation and loneliness. He is of the belief that the society should be organized so that the social and amorous nature of the human beings cannot be separated from their social existence rather be somehow united with it. Hence, he believes in a completely humanist planning based on which an industrial society can be created that its center, focal point and destination are growth and perfection of the human beings and 
not maximization of production and consumption.

According to the aforementioned materials and considering the course of modernity in Iran, we are condemned to think about our destiny in the light of modernity and, in fact, we should look at modernity as our definite fate; due to the same reason, since Fromm lived in a modern era of the west and he has coped with modernity and its outcomes years before us, he has been selected amongst the other thinkers in the present article so that his ideas and notions can be used for an investigation of industrial and modern society and also to analyze the contingent positive and negative results thereof. Put it another way, it can be stated that Fromm's perspective about loneliness stems from his subtle understanding of the conditions in the modern era of the west, to wit industrialization and modernity era; and, because we are now experiencing the conditions of the then western world, contemplation over Fromm's perspective can lead us to a better conception of our current status.

Since the social relations are centers of all humans' life, choosing loneliness as the focal point of the present study is not surprising. On the other hand, considering the various outcomes of loneliness and the bilateral effects that it creates in various individuals and, subsequently, in various communities, the deep and scrutinizing investigation of this concept seems necessary. Thus, the present study aims at recognizing and understanding Fromm's perspective regarding loneliness. Also, the current research paper intends clarifying the outcomes of loneliness in education and upbringing. To put it another way, the present study seeks elucidating the relationship between education and loneliness according to Fromm's conceptualization thereof. On the other hand, the present study also tries identifying and elaborating the conceptual and fundamental basics of loneliness in Iranian culture for various reasons, including for the discrepancies existing in conceptualization of loneliness, especially due to the diversity of the cultures.

In a short glance at the efforts and plans offered for recognizing loneliness, the present study attempts taking another step forward for subtle and more comprehensive investigation, recognition and comprehension of this concept. On the other hand, considering 
the prior efforts, the present article believes that "philosophical approach" to the issue, especially from the perspective of the existentialist philosophers and according to Erich Fromm's ideas and notions, can cover the weak points of the prior studies and works to some extent and open a promising road to the better recognition of loneliness amongst the various social classes. Due to the same reason, efforts will be made herein to accomplish the aforementioned goals via finding answers to the following questions:

1) What are the concept and nature of human loneliness according to Erich Fromm?

2) What accomplishments will be made for education by Erich Fromm's perspective?

\section{Theoretical Foundations and Study Background}

It can be generally stated that loneliness has been and is the human beings' global concern. Feeling of loneliness is an influential, pervasive and unescapable phenomenon that would afflict every human soul, disregarding age, race, gender, culture and social situation (Rokach, 2003; McLean,
2006). The gist of the philosophical schools' words about loneliness is that the concept is the most essential part of the human nature and that the human beings are incumbently urged to face this nature under any circumstances. The ancient Greek myths till Aristotle's mission and Plato's conversations are all indicative of the idea that loneliness has been formed based on western thoughts from Hellenistic period to the modern era. Mywskwwych reveals in his book that how the human beings have always carried a feeling of deep loneliness and expressing this horrible feeling in various ways.

Experiencing loneliness is a global issue that all human beings have more or less experienced it and have had it accompanied their lives. In other words, many of the individuals from various races, cultures, social classes and in different ages and times each feel such loneliness (Berguno et al., 2004). Based on existentialism, loneliness expresses the nature of a human being who has been born alone, lives alone and dies alone; therefore, this perspective concentrates on the idea that how individuals admit loneliness and live with it. Existentialists believe that the human beings are originally alone 
because all human efforts for establishing relationship such as their use of verbal and nonverbal instruments would finally reach an end and all of us will be finally alone in the end of the day (Gifford-Smith and Brownell, 2003). Rahimzadeh et al., 2012, showed in their study that although existentialist loneliness has always been investigated and measured since the first studies on loneliness till now in the texts and scales, they are most often proposed in the form of an independent concept that is structurally different from loneliness; or, it can be stated that it is felt under special conditions. In fact, the experts (for example Belcher, 1973; Mayers et al., 2002; Ettema et al., 2010) believe that the existential loneliness intrinsically exists in every individual and it is related to the mankind's fundamental feeling of loneliness; but, awareness of being lonely often comes about when an individual is in danger or faced with death.

Gottman 1997, applies social isolation as an equivalent to loneliness. Perlman and Peplau 1982, define loneliness based on the gap between the optimum levels and the existent levels of the individuals' social relations considering the qualitative and quantitative aspects. In their mind, the premises of loneliness as well as the gap and distance between an individual's ideals (what s/he wants) and accomplishments (what s/he has gained) are laid on the foundation of the interpersonal relations and sincerities. The wider the gap and distance, the more the loneliness would be felt.

Generally, the majority of the recent definitions as an example (Bahr and Harvey, 1979; Chelune, Sultan and Williams, 1980; Saklofske et al., 1986) have emphasized that loneliness is a negative emotional experience originating from the absence of relations or interpersonal communication conflicts based on which the individuals would feel insincerity in respect to one another. On the other hand, personality theoreticians are of the belief that loneliness is a fundamental anxiety that is obtained from the absence of sincere and close relationships with others. Perlman and Peplau (1979, cited in Saklofske et al., 1986) have subsequently offered a definition of loneliness that has been agreed by the majority of the researchers. According to those definitions, it can be stated that loneliness is an unpleasant emotional experience gained following the 
mismatch between the real interpersonal relationships and the individual's ideal relationships. Besides accentuating the emotional index of this concept, such a definition of loneliness also puts stress on the cognitive element, as well. The emotional aspect of loneliness entails quantitative or qualitative perception of the social relations in contradiction to what an individual expects (cited in Galanaki, 2004).

It is worth mentioning that although loneliness is influenced by objective and quantitative properties of the social relations like the frequency of the contacts or number of the friends, it is substantially influenced by the mental and qualitative evaluations of these relations such as the positive or negative appraisals, feeling satisfaction or dissatisfaction about the relations or the feeling of social agreeability or rejection. The evidences are also signifying the idea that the lonely and otherwise individuals do not differ much in terms of their daily activities or the amount of time they spend alone. Thus, loneliness is vividly distinct from the objective and visible state of physical aloneness or social isolation and solitude (Heinrich and Gullone, 2006). Loneliness is an unpleasant experience that might even occur when surrounded by other individuals (Larson, 1990). But, aloneness or social isolation with its only property being the others' absence in the periphery of an individual (Horowitz and French, 1979) is pleasant to many of the people, especially when they need tranquility and concentration (Suedfeld, 1982, cited in Bedard et al., 2005). It has to also be pointed out that solitude is an objective, purposive, useful and constructive demonstration of aloneness that can result in the fostering of creativity, contemplation on self, selfregulation, focus, thinking and identity formation (Buchholz and Catton, 1999) and it is completely necessary for perceiving the human personality if it is performed for deep meditation and revelation (Wayne Dayer, 2008). Generally, one substantial and important distinction between loneliness and social isolation is that the former is a conscious experience of the ego-dystonic type including a motivational dimension emitting from the desire in being with other individual(s) (Galanaki, 2004). To put it differently, in loneliness, disregarding an individual's being with and at the side of the others, s/he is found in urgent need for being with others (Mullins, Johnson and Anderson, 1987). 
In distinguishing between aloneness and loneliness, this can be pointed out that alones or social isolation is a voluntary state controlled by an individual; solitude, as well, is a state of aloneness that points to a conscious choice; however, loneliness is an unwanted and involuntary solitude (Wikipedia, 2007).

It is also noteworthy that it is of great importance to investigate the effect of loneliness on academic achievement in education system. The research by Guay, Bovin and Hodgese indicated that loneliness influences the students' perceptions of self-efficacy; hence, it is considered as a negative predictor of academic achievement. There are other studies, as well (as a specimen Larson, 1999; Rotenberg and Morrison, 1993, cited in Heinrich and Gullone, 2006) expressing that loneliness leads to academic decline. Khayyer and Hossein Chari 2003, conducted a research for investigating the effectiveness of the loneliness conceptualized by Asher et $a l ., 1984$, in Iranian students. The results signified the existence of negative and significant relationship between selfesteem and loneliness and insignificant relationship between loneliness and academic achievement. In the studies by Deppe 1987, as well, no significant correlation was documented between loneliness and academic achievement; but, it was found out in the study by Ginter and Dwinell 1994, who examined the relationship between loneliness, selfesteem and academic performance that there is a negative relationship between loneliness and self-esteem and a positive relationship between loneliness and academic achievement and that loneliness explains about $24 \%$ of the variance.

It can be discerned according to the theoretical foundations and the prior research that loneliness would be followed by various outcomes. A vast spectrum of the social pains and psychological diseases like depression, anxiety, phobia, schizophrenia, paranoia, etc. or social deviations like violence, aggression, delinquency, addiction, suicide, etc. are all somehow related to the distantness form the norms and, finally, all these cases are somehow related to solitude and loneliness. All in all, the investigation of the prior studies indicated that occasional themes of human loneliness can be seen in all religions from both eastern and western parts of the world but it has not been dealt with in details; it is only that a small part of the various religions' theosophy 
can be excluded for their expansion of such religious themes regarding the human loneliness and acquired results thereof. On the other hand, it seems that loneliness and feeling lonely have been less dealt with philosophically and the majority of the studies conducted in this regard have sufficed to the offering of the psychologists' perspectives. In addition, attentions have been predominantly directed in education to academic achievement and the negative and detrimental aspects of loneliness while, as it is believed by many of the thinkers and philosophers, loneliness is not only not detrimental in some occasions but it is also very much necessary. Moreover, the ideas and notions by such thinkers as Erich Fromm have been less frequently taken into account in Iran in such a way that he has not been given a specific niche in Iran's psychological faculties and there is no chair dedicated to the recognition of Fromm's perspectives and ideas. Thus, neutrality of the psychological departments and, sadder than that, the educational faculties has caused the Iranian university students not to come to the recognition of one of the most prominent psychological figures of the world; this is while Erich Fromm is recognized as an influential psychologist in the global community and he is recalled as one of the most well-known and popular faces of psychology worldwide.

\section{Study Method}

Generally speaking, methodology is the most important part of scientific and philosophical activities. The current research is a qualitative study in terms of its plan and it has been conducted based on analyticalinferential method. Study methods are in fact enumerated amongst the tools of attaining the truth. The study methods are numerous and each method helps the unraveling of the truth to some extent. In every research, the researcher tries selecting the best and the most appropriate method that is the one better assisting the researcher in comprehending the phenomena. Thus, the recognition of the existent realities, figuring out their interrelationships, better understanding of the subject and, resultantly, finding a better answer to the study questions and making sensible and logical conclusions necessitate the selection of a proper instrument and method. 
The current paper is of the normative research type. In these types of study, it is endeavored to identify the goals, norms and standards for individual and social behaviors of the mankind based on which the human actions can be guided; to put it another way, in normative philosophies, guidelines are presented for indicating the way the teachers and instructors should and should not determine goals, contents and methods of education. So, the present article uses these notions by Erich Fromm to deduce implications for education and, then, pays attention to the positive and negative aspects of loneliness to offer appropriate solutions for finding a way to confront the concept in the members of the society. Furthermore, in regard of the information gathering method and tool used in the present study, it has to be stated based on the raised questions and the article's subject that the study takes advantage of document and evidence investigation method because, as believed by Maykut and Morehouse 1994, this method enjoys more comprehensiveness and objectivity in comparison to the other qualitative methods (Bagheri, 2011).

\section{Discussion and Investigation}

Erich Fromm is a theoretician who found a new base in social psychoanalysis, culture and personality, in anthropology, psychology, philosophy and critical and radical sociology, especially in regard of social changes and construction of the future humanoriented communities. The important index of this base is his human-oriented perspective. The special aspect of Fromm's humanism is the recognition of the role and importance of human being in the process of society and history formation. In his normative humanism, he seeks establishing a type of society for the human beings who get involved therein in discovering the perfection path and meaning of the universe so that they can eventually learn love and perfection. There is no doubt that every thinker's thoughts stem from his or her basics, presumptions or the subjective principles $\mathrm{s} /$ he has learnt before or has had them intrinsically institutionalized in him or her or has assumed them in a default manner. Erich Fromm, as well, is not excluded from this axiom in his offering of his ideas and notions. He has been impressed by many philosophers, psychologists and thinkers before him, 
like Spinoza, Marx, John Dewey and Freud. The philosophers and scientists who have given color to Erich Fromm's ideology and such great figures as Plato, Aristotle, Epicurus, Spinoza, Spenser, Immanuel Kant, Friedrich Nietzsche and, even, Stirner and, finally, Marx, Freud and Dewey can be pointed out amongst them have risen up from various, occasionally paradoxical, horizons. Keeping all these in mind, it seems that Fromm, with his deep respect for the pioneers of the global civilization, has made a lot of efforts not to remain bound to a given school and, contrarily, deal, in what expressed by the great wayfarers of the path of truth, with those parts forming the main body of his humanist mindset; this has caused various epithets to be given to Fromm in such a manner that he is sometimes called a "revisionist Freud", sometimes a "humanist socialist", sometimes a "revisionist", sometimes "social scientist", sometimes "an idealist bourgeoisie" and sometimes an "individualist liberal".

Generally, Fromm works in psychology but with inclinations towards sociology. Like Aristotle, he sees mankind as an essentially social animal that needs relationship with the other human beings and with intrinsic virtues and faculties. He generally accepts Freud's essential observations and has also been influenced by Hegel and Marx and believes that the human history is a story of efforts made for freedom but he does not unduly follow any of these masters in any of the fields and tries opening a new way through criticism and deductions to offer a maximally new vision and leave the ivory tower of the theoretical systems to be amidst the people.

Considering all the aforesaid materials, Fromm is a thinker who is mostly famous as a social-psychological theoretician. Fromm's intellectual content is, for its most substantial part, comprised of not believing in the idea that the human personality has been formed by the cognitive-biological forces featuring instinctive nature and that it is flexibly guided by these forces. He imagined that the human personality is deeply influenced by social, economic, political and historical forces and believed that sick society fosters sick people. In opposing Freud, Fromm does not realize sexual factors as the force primarily shaping normal or neurotic behavior rather he knows human personality as being controlled by social 
and cultural forces both of which impact the individuals within the framework of culture and global forces that have influenced the mankind in the course of history. In fact, his goal is devising a theory about the various human desires stemming from the humans' existential conditions by believing in the idea that an individual creates his or her own nature. Fromm was of the belief that we should investigate the history of the mankind so that we can understand and realize such creation.

Important and independent subjects can be observed in the investigation of Fromm's ideas and notions, including human beings' radical efforts and conflicts for obtaining freedom with such interpretations as escape from freedom, human beings' psychological mechanisms for retrieving security, human beings' psychological needs, constructive and non-constructive manners, human being's nature and so forth; but, the main subject of all Fromm's writings is that an individual feels loneliness and solitude in this world because s/he has been separated from his or her nature and such solitude and loneliness cannot be seen in any other living being or animal. Fromm flourished the theory that the more the human beings attain more freedoms the more they will feel lonely. This way, freedom becomes a negative attribute that should be avoided. Thus, to Fromm, the world and the destiny of the mankind is the very epic of Prometheus in his human chains and efforts for relieving oneself from his constraints. The story of mankind's life in the one-hundred-year history of his history, meanwhile retelling a constant endeavor for supplying himself with his preliminary needs, is a painful story for escaping his loneliness and isolation. In Fromm's opinion, the mankind has always been in a man-too-man fight with an essential paradox in the entire course of history. This paradox lies in the idea that the human beings are intrinsically lonely creatures while being also a part of the whole universe. He knows that he is willingly or unwillingly alone in resolving the essential problems of his own and his fellow mankind's life. He also knows that he is the one who should eventually make all the decisions and judgments alone and he is also aware that he is after all related to the nature and the other humans and that his felicity or misery is incumbently directly related to the nature and type of the relationship he would establish with the other people. 
Fromm's perspective is valuable in that he believes in the veracity of his knowledge and human wisdom and considers mankind as the absolute goal of human efforts and he only assesses the previous and present schools with the touchstone that how much they have been effective in solidifying the human position and sublimation of the mankind's honor, integrity and perfection; thus, Erich Fromm's ideology can be essentially termed humanist and altruist. In 1964, Fromm believed, according to his optimistic approach towards the human nature in his book "the heart of the man, its genius for good and evil", that the mankind is not a part of the nature like other animals for his enjoyment of knowledge, awareness, intelligence and ability of overcoming the nature; in fact, he held that the mankind goes beyond the nature hence, although being exposed to the natural principles and regulations, he cannot change them and finds oneself in a state of wandering and solitude; due to the same reason, the mankind has been saved of the preliminary dependency on the nature which is a characteristic of animal life and he is informed of his loneliness and separation, inability and ignorance and also of his sudden death and birth for his possession of wisdom and thought.

On the other hand, Erich Fromm did not realize the needs mankind has been conditioned on them as the only coercive part of the human nature. He believed that the other part of the human needs depends on his relatedness to the outside world and avoidance of loneliness and that it, instead of being based on the body actions, is rooted in the essence of the human life's method and action. The result of the complete loneliness and separation would be psychological distress the same way that hunger leads to death. It is also important to state that, in Fromm's opinion, relationship with others does not mean physical contact because an individual may spend years in loneliness and still be connected to the thoughts and values or, at least, the social organizations granting it a sense of "attachment and communion". On the other hand, an individual may live amidst the people and yet find oneself defeated by a feeling of absolute separation that, if exceeding a certain limit, would result in dementia represented by schizophrenic disorders. Thus, in his book "the art of loving", Fromm calls the absence of relationship 
with the values, signs and organizations as an "ethical loneliness" and believes that ethical loneliness is as intolerable as physical aloneness; or, better said, aloneness only surpasses the tolerance limits when ethical loneliness is latent therein. In other words, the mankind always fears loneliness and, amongst various kinds of loneliness, ethical loneliness is the most dreadful one. In fact, we have been made for social contact and, lacking a sufficient amount of it, we would be inflicted with malign consequences exposing our life to threat; we would lose our psychological balance and we will be afflicted with physical decline.

Undoubtedly, this unending discussion will not be terminated with the readers' familiarization with Erich Fromm's ideology and upon finishing the reading of this article and the riddle of loneliness and its various related aspects, as well, can never be completely resolved in the form of a mathematical and/or scientific equation as long as human beings live on earth. However, the present article might incite a thousand thoughts for resolving this puzzle and shed light from various angles on this complex problem for those interested in loneliness and having figured out the vital importance of this phenomenon in life.

\section{Conclusion}

It is now for years that there are speeches made about the humans' inherent need for group, social life and the effect of this form of life on the mental and physical health whereas loneliness and its role in life have been less frequently discussed; thus, the present article was conducted with the objective of investigating Fromm's ideas and notions about loneliness. The results of these investigations indicated that loneliness is composed of two paradoxical dimensions: 1) the detrimental aspect of loneliness that expresses the beliefs of many of the psychologists about loneliness. Such a problem is known in the USA as "loneliness epidemy"; on the other hand, England appointed a new minister under the title of "Loneliness Affairs Minister" who, as England's prime minister puts it, is responsible for investigating the "bitter reality of the modern life", to wit loneliness. In Fromm's opinion, the contemporary human being has become forlorn in the face of modernity and socioeconomic forces created by he 
himself the same way that the primitive human being was defeated and shelterless before the power of nature; due to the same reason, loneliness is the sad reality of the modern life to many of the individuals, especially the Iranian people. Based on such a belief, loneliness is harmful to the healthiness of the psyche and mind. The results of the extensive research show that the detrimental loneliness can be accompanied by numerous psychological problems like depression, paranoia, social anxiety and personality disorder. 2) The constructive aspect of loneliness has been expressed by many of the philosophers many of whom consider loneliness as a positive concept that is necessary in many of the cases. For instance, everybody may occasionally want to be alone because they can do their tasks with a higher precision and concentration when they are alone; they would reach a higher deal of creativity and they can better drive away their negative and stressing thoughts.

Although loneliness can be followed by some advantages and benefits for the mankind, it is not always devoid of disadvantages. As it was mentioned, some consider loneliness pleasant and some others see it irritating; disregarding these two conflicting feelings, the basic concept and axiom is directed at the idea that continuation of loneliness can be accompanied by many risks and harms. To put it another way, loneliness can lead to depression, anxiety, isolation and so forth and, at the same time, it can foster growth, selfconsciousness, self-esteem, creativity, facilitation of self-reflection, selfregulation, identity formation, mindfulness, thinking and learning (Heinrich and Gullone, 2006). Of course, the emergence of the side effects of loneliness is often not selective rather these side effects are imposed on the individuals. The important thing here is making a distinction between antisocial individuals and the group that consciously chooses loneliness. In fact, the individuals who fear appearing in the society have a sort of disorder that can be accompanied by serious outcomes like violence, aggression and depression; this is while loneliness is recounted as an option for the opposite group and this is a choice providing them with an opportunity to think. In fact, to these individuals, loneliness is a chance of dealing with personal or desired tasks. The thing that is of importance here is the 
awareness of the issue that not every social person with vast communications and relationships is necessarily mentally healthy; on the other hand, loneliness is not always a sign indicating the antisocial personalities.

One of the most important indices of Aristotelian ethics and, subsequently, philosophical ethics is the golden moderation and/or middle-way theory. Pointing to an inscription in Delos Island in his Nicomachean Ethics, Aristotle expresses the history of tendency towards middle way and moderation in ancient Greece as follows: "the more beautiful thing is the one featuring higher moderation and fairness". According to moderation theory, the criterion for virtuousness is that the human beings should observe the middle way in every action and stay away from deficiency and extremity that are both deemed as inferiority. It can be stated based on Aristotle's theory that loneliness is a feeling that, if balanced, can be constructive and result in selfknowledge, fostering of contemplative thinking, self-discovery and selfawareness and, if going to extremes, it would be followed by many adverse effects.
It can be generally stated that the thing effective in the corroboration of social interactions and controlling loneliness is related to the teaching and learning of life techniques and skills and the more an individual becomes versatile and competent in this area the lesser s/he would be likely to become alone. Therefore, to reach the intended balance, students would need learning of the loneliness skill and the quality of taking advantage of constructive loneliness; furthermore, instructing the solutions and methods of coping with the detrimental type of loneliness at schools is necessary. Therefore, the spaces in schools and education systems should be in such a way that the students can learn social skills so as not to become loners preferring isolation and solitude. Fromm was of the belief that education system of a great many of the communities should be metamorphosed because he believed that a large part of the today's world distress is the product of ill education systems. Since the results of some studies regarding the positive effect of loneliness on academic achievement such as (Ginter and Dwinell, 1994) have caused worries in the educational systems, it is necessary for the teachers of schools and education officials to take 
a long leap towards the optimum use of positive aspects of loneliness and devising solutions for reducing its detrimental effects so that the riddle of loneliness can be best recognized and exploited the same way and as much as Aristotle knew virtuousness as the middle way of deficiency and extremism.

According to the fact that learning communication techniques is the most important indicator in strengthening the social interactions, it can be stated that the individuals lacking such a capability will be always prone to loneliness. Cutrona 1986, expressed in a study that the individuals feeling loneliness and experiencing a limited network of friendship are found with social skill deficits more than the others. In other words, the individuals with loneliness, limited friendly relationships and lack of self-confidence will have their abilities downgraded in symbiosis with the others and the establishment of a sincere relationship between the teacher and the students in group activities can usually unravel and fortify this skill in them; therefore, the schools and education systems should endeavor to provide the students with the ability to experience cooperation, symbiosis and human right via allowing them perform various group activities so that they can figure out why it is important to observe one another's rights; that is because understanding such an important issue would corroborate sense of duty in them. Generally, children's friendships with others become as important as their familial relationships when they reach school age. Children are thirsty of being accepted amongst the others of the same age. As an Islamic thinker, Qazzali adopts a completely intellectual and inherent look at friendship. He realizes friendship as being inherent in human beings and believes that the humans love the thing contributing to their survival and perfection. Thus, before and more than any other thing, the human community needs peace, altruism, cooperation, tolerance and openness to criticism that should be nurtured since childhood, particularly at schools; it is also notable that many of the possible harms can be prevented while preserving friendship and sincerity, as necessities of the adolescence, thereby to minimize the harms of such friendships via teaching the life skills, including the ability of saying "No" and, especially, exhibition of "decisive behavior", to the students. 
Erich Fromm has always expressed his dissatisfaction of the systems individually imposed by the closed, predefined and non-creative educations system onto the children. That is because, as believed by Fromm, the activities that are creative, groupbased and lacking compulsory assignments can strengthen compliance, interaction and mutual understanding between students, teachers and their families. It can be stated based on this perspective that one shortcoming of the current education system is that the students are evaluated by obligatory assignments and negative competitions with one another. This method of assessment is faulty in that the weak students would feel after a short while that they cannot prove a reasonable presence in the classroom so they would lose their motivation for making efforts and prefer to stay away from their classmates and this instigates negative loneliness in them. Based thereupon, offering effective strategies for preventing academic failure and fighting with loneliness via paying attention to individual differences and creation of motivation in the classroom seems necessary.
Another effective way for increasing the mental health in the society and reducing loneliness is creation of happiness in schools. As an important social institution, schools can bring more happiness to the society via setting the grounds and programs. If the zeal for living is fortified in school, it will spontaneously influence the school. Happy persons have control of their lives and they are hopeful, far-sighted, purposive and responsible and approach life more positively and remain robust as mountain in confrontation with problems and hardship. Psychologists know happiness and joyfulness as propellers of the human activities and, subsequently, realize happy society as a successful one. Creation of identical opportunities for all the students and their being accepted by the others of the same age are amongst the other indicators of happiness and prevention of the emergence of loneliness. Therefore, firstly families and secondly other institutions like schools as well as the other culturalreligious institutions are amongst the organs that can cause the expansion of happiness and creation of happiness and joy in the society. Since everyone is well-aware of the role of the teachers and schools, therefore, it is via establishing 
bonds and keeping balance between these three important elements and creation of a happy school that we can remain hopeful in rearing of healthy and efficient individuals for a successful society.

As it was mentioned, some philosophers are of the belief that loneliness, though being a painful experience, can cause growth and consciousness in the individuals and it can also be envisaged as a potential for their healthiness following which the ground is paved for the establishment of a subtle and meaningful relationship with others (Nilsson, Lindstrom and Naden, 2006; Yalom, 2018). In fact, the existentialist researchers posit the existence of such loneliness under the title of "privacy" wherein the individual devotes some time to oneself away from tumult and social pressures and demands and gets involved in performing things $\mathrm{s} /$ he is interested in or fostering his or her intellectual and mental power (Nilsson et al, 2006 and Long et al., 2003). Therefore, schools and, subsequently, teachers should value the positive aspect of loneliness because this aspect of loneliness can cause an increase in the creativity and learning in younger ages. The lonely children would more engage in the discovery of their peripheral world and they are usually found with more knowledge as compared to their busy counterparts. Thus, in order to be able to correctly take their growth stages from the childhood to adulthood, individuals should be provided with more free time during childhood so that they can corroborate their creativity, curiosity and thinking. In fact, failure in acting freely and being forced to perform all their life affairs based on predetermined programs, the children would not be able to blossom all their internal abilities in a complete manner.

In other words, while loneliness can be severely frustrating and unpleasant, guiding the children on such occasions towards the use of their imagination and mental faculties would fortify creativity in them. In fact, constructive loneliness increases the chance to learn, leads to the individual's better understanding of the self and helps everyone more carefully look at inside oneself and the exterior world following which they would become inclined towards novel works and new experiences; but, nowadays, due to the development and advance of the instruments, mass communication instruments and, in one word, modernity, 
children's access to these instruments has become easier and there is left no time for them to activate imagination and creativity. Thus, it is better if schools could dedicate some time to such activities as painting, multi-individual, group and highly active games and so on because these activities set the ground in them for growth and improve their imagination power.

In the end, according to all the above-mentioned materials and based on the investigation of Erich Fromm's perspectives and notions, it can be stated that Fromm has offered a unitary interpretation of the interaction between the mankind and the community. He has made us aware of the mutual and constant effects of cultural, social, economic and psychological factors on the human nature possibly more than any other theoreticians. Disregarding the credibility or otherwise of his interpretations and specific renderings to everyone, Fromm has shown it to us that the human beings are not exclusive product of a single collection of forces rather they are products of the mutual effects of various forces and events. $\mathrm{He}$ has forced us to go beyond the boundaries of a study field and he has continuously instigated us to actualize the perfection and fostering of a more human society and pay attention to the unpleasant outcomes of not doing so. This way, his efforts, no matter what effects they would bring about, expand well beyond the psychoanalysis or psychology and incorporate a vast spectrum of social issues that have drawn everybody's attentions. We are living in a community that many of its essential values should be revised so that it can be rendered consistent with the variable world. Thus, the study and investigation of all Fromm's works is suggested to everyone for the emergence of a world that can be governed by the sound human love.

\section{Acknowledgement}

The authors thank all to their families, husband and dear teacher Doctor Babak Shamshiri for their kind cooperation in this study.

\section{References}

Abedi, A., and Tabrizizadeh Esfahani, R. (2015). Comparative evaluation of Aristotlean moderation theory and Islam's ethical theory. Seasonal journal of the philosophy of religion, 11(4). 
Ahmadi, Babak. (2015). Meaning of modernity. $9^{\text {th }}$ Edition, Tehran, Markaz.

Ahmadi, Babak. (2016). Modernity and critical thinking. $10^{\text {th }}$ Edition, Tehran, Markaz.

AmirMahallati, Mohammad Ja'afar. (2018). Friendship as an ideology. $1^{\text {st }}$ Edition, Tehran, Hermes.

Arjomand, Elham. (2008). A glance at Erich Fromm's notions. Afarinesh Newspaper, Part Five.

Asher, S. R., \& Hymel, S., \& Renshaw, P. D. (1984). Loneliness in children. Child development., Vol. 55, pp. 14561464.

Asher, S. R., \& Paquette, J. A. (2003). Loneliness and peer relations in childhood. Current Directions in Psychological Science., Vol. 12, No. 3, pp. $75-78$.

Bagheri, Khosrow., Sajjadiyeh, Narges and Tavassoli, Tayyebeh. (2011). Approaches and methods of in the study education philosophy. $1^{\text {st }}$ Edition, Tehran, cultural and social research center of the ministry of science, research and technology.

Bahr, H. M., \& Harvey, C. D. (1979). Correlates of Loneliness among widows bereaved in a mining disaster. Psychology Reports., Vol. 44, pp. 367385.

Bedard, Luke., Deziel, Joseph and Lamarche, Luke. (2015). Social psychology. $2^{\text {nd }}$ Edition, tr. Hamzeh Ganji. Tehran, Savalan.

Belcher, M. J. (1973). The measurement of loneliness: A validation of the Belcher Extended Loneliness Scale (BELS). Unpublished doctoral dissertation, Illinois Institute of Technology.

Berguno, G., \& Leroux, P., \& McAinish, K., \& Shaikh, S. (2004). Children's Experience of Loneliness at school and its Relation to Bullying and The Quality of Teacher Interventions. The Qualitative Report., Vol. 9, No. 3, pp. 483-499.

Bochensky, A. M., and Khorasani, Sh. (2005). Contemporary European philosophy. $\quad 3^{\text {rd }}$ Edition, Tehran, scientific and cultural publication center. 
Buchholz, E. S., \& Catton, R. (1999). Adolescents Perceptions of aloneness and loneliness. Adolescence., Vol. 34, pp. 203-213.

Chelune, G. J., \& Sultan, F. J., \& Williams, C. L. (1980). Loneliness, SelfDisclosure and interpersonal affectiveness. Journal of Counseling Psychology., Vol. 27, pp. 462-469.

Cutrona. (1986). Objective determinate of perceived social support. Journal of personality and social psychology., Vol. 50, pp. 349-355.

Dayer, Wayne. (2008). Ten secrets for success and internal peace. $1^{\text {st }}$ Edition, tr. Elham Bahrami Raad. Tehran, Pol.

De Jong Gierveled, J. (1998). A review of loneliness: Concept and Definitions, Determinants and Consequences. Reviews in Clinical Gerontology., Vol. 8, pp. 73-80.

Deppe, H. J. (1987). Loneliness and SelfEsteem as Related to Academic Achievement and Gender in College Students. Oklahoma State University. eArchve@Oklahoma State University.
Ettema, E. J., \& Derksen, L. D., \& Leeuwen, E. N. (2010). Existential loneliness and End-of-Care: A systematic review. Theoretical Medicine and Bioethics., Vol. 31, pp. 141- 169.

Fromm, Erich. (2011). Psychoanalysis and religion. $3^{\text {rd }}$ Edition, tr. Arsen Nazariyan. Tehran, Morwarid.

Fromm, Erich. (2012). Man for himself: a research on psychology of ethics. $5^{\text {th }}$ Edition, tr. Ali Akbar Tabrizi. Tehran, Behjat.

Fromm, Erich. (2015). The crisis of psychoanalysis. $10^{\text {th }}$ Edition, tr. Akbar Tabrizi. Tehran, Firouzeh.

Fromm, Erich. (2015). The lost language. $10^{\text {th }}$ Edition, tr. Ebrahim Amanat. Tehran, Firouzeh.

Fromm, Erich. (2016). Psychoanalysis and Zen Buddhism. $3^{\text {rd }}$ Edition, tr. Nasrollah Ghaffari. Tehran, Behjat.

Fromm, Erich. (2016). The revolution of hope. $7^{\text {th }}$ Edition, tr. Majid Rowshangar. Tehran, Morwarid. 
Fromm, Erich. (2017). Escape from freedom. $18^{\text {th }}$ Edition, tr. Ezzatollah Fouladvand. Tehran, Morwarid.

Fromm, Erich. (2017). Healthy society. $8^{\text {th }}$ Edition, tr. Akbar Tabrizi. Tehran, Behjat.

Fromm, Erich. (2017). The man, its genius for good and evil. $13^{\text {th }}$ Edition, tr. Giti Khoshdel. Paykan.

Fromm, Erich. (2018). May man prevail?. $10^{\text {th }}$ Edition, tr. Ezzatollah Fouladvand. Tehran, Morwarid.

Fromm, Erich. (2019). The art of loving. $33^{\text {rd }}$ Edition, tr. Pouri Soltani. Tehran, Morwarid.

Fromm, Erich. (2019). To have or to be. $17^{\text {th }}$ Edition, tr. Akbar Tabrizi. Tehran, Firouzeh.

Galanaki, E. (2004). Are children able to distinguish among the concepts of aloneness, loneliness, and solitude?. International Journal of Behavioral Development., Vol. 28, No. 5, pp. 435443.
Ghabezi, F., Pakdaman, Sh., Fath Abadi, J., and Hassanzadeh Tavakkoli, M. R. (2016). Spiritual-religious loneliness: constructing and validating a scale for assessing the positive and negative aspects of loneliness. Seasonal journal of psychology and religion, 8(1).

Ghana'at Pisheh, A. Z. (2006). Comparing the effect of individual competition, individual effort and group competition on academic achievement. Seasonal journal of education, 21(1).

Ghashgha'ei, T., and Atrak, H. (2014). Investigating and criticizing Erich Fromm's perspective about the human's inclination towards religion. Seasonal journal of religious thought, Shiraz University, 13(2).

Gifford-Smith, M. E., \& Brownell, C. A. (2003). Childhood peer relationships: Social acceptance, Friendships and peer networks. Journal of School Psychology., Vol. 41, pp. 235-284.

Ginter, E. J., \& Dwinell, P. L. (1994). The Importance of Perceived Duration: Loneliness and Its Relationship to SelfEsteem and Academic Performance. Journal of College Student 
Development., Vol. 35, No. 6, pp. 456460.

Gottman, J. M. (1997). Toward a Definition of Social Isolation in Children. Child Development., Vol. 48, pp. 513-517.

Goutak, Gerald L. (2017). Philosophical schools and educational notions. $16^{\text {th }}$ Edition, tr. Mohammad Ja'afar PakSeresht. Tehran, Samt.

Guay, F., \& Boivin, M., \& Hodgese, V. E. (1999). Predicting change in academic achievement: A model of peer experiences and Self-System processes. Journal of Educational Psychology., Vol. 91, No. 1, pp. 105-115.

Heinrich, L. M., \& Gullone, E. (2006). The clinical significance of loneliness: A literature review. Clinical Psychology Review., Vol. 26, No. 6, pp. 695-718.

Heinrich, Miziac. (2000). The history and schools of psychology. tr. Ahmad Rezvani. Mashhad, Astan-e-Ghods-eRazavi.

Hooman, H. A., Ahadi, H., SepahMansour, M., and Sheikhi, M.
352

(2011). Modeling loneliness based on spiritual wellbeing's structure, selfefficacy and satisfaction of life. Seasonal journal of psychological research, 2(7).

Horowitz, L. M., \& French, R. D. (1979). Interpersonal problems of people who describe themselves as lonely. Journal of Consulting and Clinical Psychology., Vol. 47, pp. 762-764.

J. F. Neller. (2017). Getting familiar with education philosophy. $12^{\text {th }}$ Edition, tr. Dr. Fereydun Bazargan Dailamghani. Tehran, Samt.

Jahanbaglou, Ramin. (2018). Iran and modernit: conversations with Iranian and foreign researchers about Iran's confrontation with the accomplishments of the modern world. $5^{\text {th }}$ Edition, tr. Hossein Same'ei. Tehran, Qatreh.

Karimi, Yousef. (2017). Personality psychology. $\quad 3^{\text {rd }}$ Edition, Tehran, Virayesh.

Khalaj, T. (2015). Influence of society from the perspective of Fromm. Bagher Al-Olum research center. 
Khayyer, Mohammad and HosseinChari, Mas'oud. (2003). Investigating the efficiency of a scale for assessing loneliness in the guidance school students. Journal of social and human sciences, Shiraz University, 19(1).

Kho'einejad, Gh. R., Raja'ei, A. R., and Mohebb Raad, T. (2008). The relationship between the perceived children upbringing style and the loneliness of the adolescent girls. Seasonal journal of knowledge and research in applied psychology, 9(34).

La'alifaz, A., Askari, A. (2009). Predictability of the perceived children upbringing styles and demographic variables based on loneliness of the girl students. Seasonal journal of psychological health principles, 10(1).

Larson, R. (1990). The solitary side of life: An examination of the time people spend alone from childhood to old age. Developemental Review., Vol. 10, pp. 155-183.

Long, C. R., \& Seburn, M., \& Averill, J. R., \& More, T. A. (2003). Solitude: An Exploration of Benefits of Being Alone.
Journal for the Theory of Social Behavior., Vol. 33, No. 1, pp. 21-44.

Long, C. R., \& Seburn, M., \& Averill, J. R., \& More, T. A. (2003). Solitude Experiences: Varieties, Settings, and Individual Differences. Personality and Social Psychology Bulletin., Vol. 29, No. 5, pp. 578-583.

Marshal, Cathrine and Russman, Gretchen. (2017). Qualitative research method. $5^{\text {th }}$ Edition, tr. Ali Parsa'eiyan and Sayyed Mohammad E'erabi. Tehran, cultural research office publication.

Mayers, A. M., \& Khoo, S. T., \& Svartberg, M. (2002). The Existential Loneliness Questionnaire: Background, Development, and Preliminary Findings. Journal of Clinical Psychology., Vol. 58, No. 9, pp. 1183-1193.

Mazidi, Mohammad. (2016). Advanced research method (Ph.D course lesson manual). Shiraz University, psychology and educational sciences faculty.

McCuary, John. (1999). Existential philosophy. $1^{\text {st }}$ Edition, tr. Mohammad 


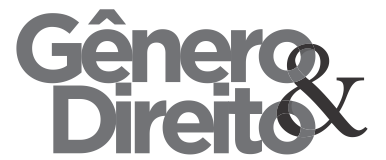

Periódico do Núcleo de Estudos e Pesquisas sobre Gênero e Direito

Centro de Ciências Jurídicas - Universidade Federal da Paraíba

V. 8 - $\mathrm{N}^{\circ} 03$ - Ano 2019

ISSN | 2179-7137 | http://periodicos.ufpb.br/ojs2/index.php/ged/index

Sa'eid Hana'ei Kashani. Tehran,

Hermes.

Mclean, R. (2006). Build social network for lonely singles. Social Loneliness. [www.cyberparent.com/you.htm]. (05/20/2006).

Mesbah, A., and Mohiti Ardakan, M. A. (2012). The investigation of the anthropological basics of Erich Fromm's perspectives. Journal of philosophical cognizance, 8(3).

Mosta'an, Mahtab. (2008). Soren Kierkegaard, "the theosophist thinker". Tehran, Porsesh.

Mullins, L. C., \& Johnson, D. P., \& Anderson, L. (1987). Loneliness of the Elderly. The impact of family and friends. In Hojat, M., \& Crandall, R. (Eds), loneliness: Theory, Research, and Applications (pp.89-104). Newbury park, California: sage publishing.

Nilsson, B., \& Lindstrom, U. A., \& Naden, D. (2006). Is Loneliness a psychological Dysfunction? A literary study of the phenomenon of lineliness. Scanding Journal of Caring Sciences., Vol. 20, No. 1, pp. 93-101.

Paul Sartre, Jean. (2018). Existentialism and human originality. $16^{\text {th }}$ Edition, tr. Mostafa Rahimi. Tehran, Niloofar.

Perlman, D., \& Peplau, L. A. (1982). Loneliness: A Sourcebook of Current Theory, Research and Theory., New York: Wiley.

Rahimzadeh, S. (2011b). Existentialist loneliness questionnaire: findings, grounds and early expansion. Seasonal journal of evolutionary psychology: Iranian psychology, No.24.

Rahimzadeh, S., Bayat, M., and Anari, A. (2010). Loneliness and social selfefficacy in adolescents. Seasonal journal of evolutionary psychology: Iranian psychology, No.22.

Rahimzadeh, S., Pour E'etemad, H., Asgari, A., and Hojjat, M. (2012). Conceptual basics of loneliness: a qualitative research. Seasonal journal of evolutionary psychology: Iranian psychology, 8(30).

Rokach, A. \& et al. (2013). Cancer patients, their caregivers, and coping 


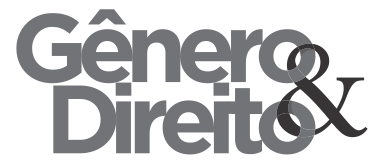

Periódico do Núcleo de Estudos e Pesquisas sobre Gênero e Direito

Centro de Ciências Jurídicas - Universidade Federal da Paraíba

V. 8 - $\mathrm{N}^{\circ} 03$ - Ano 2019

ISSN | 2179-7137 | http://periodicos.ufpb.br/ojs2/index.php/ged/index with loneliness. Psychology, Health \& Medicine., Vol. 18, No. 2, pp. 1-10.

Rokach, A. (1996). The subjectivity of loneliness and coping with it. Psychological Reports., Vol. 79, pp. $475-481$.

Rokach, A. (2001). Perceived causes of loneliness: A crosscultural comparison. Retrieved December 3, 2008, from http://findarticles.com/p/articles/miqma 3852 / is-200/ 01/ ai-n8945437.

Rokach, A. (2003). Causes of Loneliness of Those Afflicted with LifeThreatening illnesses. Social Behavior \& Personality., Vol. 31, No. 7, pp. 663674.

[http:/findarticles.com/p/articles/mi_qa3 852/is_/ai_n9216845]. (05/20/2006).

Rouznahan, David and Seligman, Martin. (2017). Abnormality psychology: psychological pathology. $17^{\text {th }}$ Edition, tr. Yahya Sayyed Mohammadi. Tehran, Arasbaran.

Sa'eidi, H., Dortaj, F., and Salimi, A. (2016). The relationship between resilience and loneliness with academic self-efficacy of the high school boy students from Baneh County. Seasonal journal of educational psychology, Islamic Azad University, Tonekabon Branch, 6(2).

Saklofske, D. H., \& Yackulic, R. A., \& Kelly, I. W. (1986). Personality and Loneliness. Personality and Individual Differences., Vol. 7, pp. 899-901.

Salimi, A. (2009). Causal model of the antecedents and outcomes of loneliness. MA dissertation, Shiraz University.

Schultz, Devon P. (2000). Personality theories. $1^{\text {st }}$ Edition, tr. Yousef Karimi. Tehran, Arasbaran.

Schultz, Devon P., and Schultz, Sydney Allen. (1997). The history of modern psychology. $3^{\text {rd }}$ Edition, tr. Ali Akbar Saif. Tehran, Roshd.

Shamlou, Saeid. (2013). Schools and theories in personality psychology. $9^{\text {th }}$ Edition, Tehran, Roshd.

Shamshiri, Babak. (2007). Education from the perspective of love and Gnosticism. $1^{\text {st }}$ Edition, Tehran, Tahouri. 
Shokouhi, Gholam Hossein. (2000).

Basics and principles of education. $11^{\text {th }}$

Edition, Mashhad, Astan-e-Ghods-e-

Razavi.

Sullivan, H. S. (1953). The Interpersonal

Theory Psychiatry., New York: Norton.

Tahmasebiyan, K., Anari, a., and Salehi

Sedghpour, B. (2010). The direct and indirect effects of social self-efficacy in adolescents' loneliness. Journal of behavioral sciences, 3(2).

Vahedi, Sh., Fath Abadi, J., and Akbari, S. (2011). Mediatory pattern of emotional and social loneliness, spiritual wellbeing, social distantness and depression of the girl university students. Seasonal journal of applied psychology, 4(4).

Wikipedia. (2007). Loneliness. The free encyclopedia. [http:// www.wikipedia. org]. (05/19/2006).

Wolf, David. (2008). Psychology of religion. $2^{\text {nd }}$ Edition, tr. Mohammad Dehghani. Tehran, Roshd.
Yalom, Erwin. (2018). Existential psychotherapy. $10^{\text {th }}$ Edition, tr. Sepideh Habib. Tehran, Nay.

Yaspres, Carl. (2015). The wisdom's passageway. $2^{\text {nd }}$ Edition, tr. Mahbod Irani Talab. Tehran, Qatreh.

Yousefi, Naser. (2014). Recognizing Erich Fromm with an emphasis on child and children education. $1^{\text {st }}$ Edition, Tehran, Markaz.

Zaighami Mohammadi, Sh., and Tajwidi, M. (2012). The relationship between spiritual health and frustration with social skills of the adolescents with thalassemia major. Seasonal journal of modern healthcare, Medical Sciences University, Birjand Branch, 8(3).

Zarnaghash, M., Gholamreza'ei, S., and Sadeghi, M. (2017). Codifying a model of loneliness based on coping strategies, spiritual wellbeing, depression and life satisfaction in teh daughters of the warinjured fathers. Seasonal journal of psychological methods and models, $7(26)$. 
Periódico do Núcleo de Estudos e Pesquisas sobre Gênero e Direito

Centro de Ciências Jurídicas - Universidade Federal da Paraíba

V. 8 - $\mathrm{N}^{\circ} 03$ - Ano 2019

ISSN | 2179-7137 | http://periodicos.ufpb.br/ojs2/index.php/ged/index

Zibakalam Mofrad, Fatemeh. (2008).

Evolutionary trend of philosophical

thoughts in the west. $1^{\text {st }}$ Edition, Tehran,

Tehran University 